\title{
Carbon nanofibers grown on metallic filters as novel catalytic materials
}

\author{
P. Tribolet, L. Kiwi-Minsker* \\ Ecole Polytechnique Fédérale de Lausanne (EPFL), LGRC, CH-1015 Lausanne, Switzerland
}

Available online 26 April 2005

\begin{abstract}
Carbon nanofibers (CNF) were synthesized on sintered metal fibers (SMF) filters of nickel and Ni-containing alloys (Inconel, stainless steel (SS)) by thermal chemical vapor deposition of ethane in the presence of hydrogen at $\sim 660{ }^{\circ} \mathrm{C}$. The CNFs were formed directly over the SMF filters without deposition of metal particles. The catalytic active sites leading to the CNF formation were attained by oxidation-reduction of the SMF filter. The CNFs present platelet morphology as determined by X-ray diffraction and transmission electron microscopy. The CNF/ SMF composites have thin carbon layer in the microns range strongly anchored to the metal surface. The initial open structure of SMF filters is preserved. Scanning electron microscopy together with temperature programmed oxidation suggests the formation of uniform CNFs deposits on $\mathrm{SMF}_{\text {Inconel }}$ with fiber's diameters in the range of $70 \mathrm{~nm}$. Carbon deposits with a different nature were observed over $\mathrm{SMF}_{\mathrm{Ni}}$ and $\mathrm{SMF}_{\mathrm{ss}}$.

The $\mathrm{CNF} / \mathrm{SMF}_{\text {Inconel }}$ composites have high specific surface area due to mesopores of CNFs, high thermo-conductivity and open 3D macrostructure. This is advantageous for catalytic applications, especially during the catalysis of highly exo/endothermic reactions in reactors with structured catalytic bed.
\end{abstract}

(C) 2005 Elsevier B.V. All rights reserved.

Keywords: Carbon nanofibers; Sintered metal fiber filters; Carbon/metal composites; Structured catalyst

\section{Introduction}

Carbon nanofibers (CNF) are novel carbon compounds, which have unique mechanical, electronic, chemical and physical properties [1-3]. They are also used as catalyst and catalytic supports $[4,5]$. Compared to activated carbons, CNFs offer high specific surface area due to meso-pores without micro-porosity, thus preventing internal diffusion limitations. In addition, their graphitic structure leads to specific metalsupport interactions, which improves the catalytic activity/ selectivity. Thus, CNF supports have been reported to induce an increase in the catalytic performance of nickel nanoparticles during hydrogenations of 1-butene, 1,3-butadiene [6] and crotonaldehyde [7]. Other reports have shown advantageous properties of CNFs catalytic supports [8-10].

The CNF synthesis involves supporting of metallic $(\mathrm{Ni}$, $\mathrm{Fe}$, or alloys) particles on oxides or other materials for carbonization of gaseous precursor by catalytic pyrolysis

\footnotetext{
* Corresponding author. Tel.: +41 21693 3182; fax: +41 216933190.

E-mail address: lioubov.kiwi-minsker@epfl.ch (L. Kiwi-Minsker).
}

(thermal CVD synthesis). Due to the reaction of active metallic particle with precursor gases, several vapor-grown CNFs were obtained with different crystalline orientation. The majority of the synthesis requires considerable post-processing involving further CNFs purification with final product in the form of fine powders. For several applications like electrode materials, absorbent media for filtration, and catalytic materials, the CNFs have to be reattached on the support with suitable macro-structure. To avoid this operation, one approach is the CNFs synthesis directly on the support material. Vieira et al. proposed to grow CNFs on graphite felt [11]. Other groups have synthesized nano-carbons directly on monoliths [12,13], carbon blacks [14] and on a large area of sodalime glass by CVD synthesis of acetylene [15]. But achieving stable anchoring and uniformity of CNFs still remains a challenge, especially on metallic surfaces.

In this work, we propose the use of sintered metal fibers (SMF) filters as catalysts and supports for the growth of CNFs. Sintered metal fibers filters have uniform micron size filaments sintered into a homogeneous 3D structure. They are characterized by porosity up to $80-90 \%$, large 
permeability and excellent filtrating properties with a low pressure drop through the bed during reactor operation. Fibers made of special alloys (stainless steel, Inconel, Fecralloy) exhibit high mechanical strength, chemical and thermal stability. High thermal conductivity of the metal fiber matrix provides a radial heat transfer coefficient twofold higher compared to randomly packed catalytic beds [16]. This results in nearly isothermal conditions when used as catalytic materials for highly exo/endothermic reactions. This fibrous matrix acts also as a static micromixer avoiding channeling.

This study addresses the effect of the SMFs composition and the necessary pre-treatment/activation steps for CNF growth directly from the support surface. The gas's concentrations, temperature and time of the CVD synthesis were also studied regarding the CNF morphology, graphitic structure, density and uniformity of metal surface coating by scanning electron microscopy (SEM), transmission electron microscopy (TEM), X-ray diffraction and temperature programmed oxidation (TPO) methods.

\section{Experimental}

\subsection{Materials}

Three types of commercially available sintered metal fiber filters were used as catalysts and catalyst supports during this study:

- Stainless steel (SS), sintered AISI 316L (composition: Cr: 16.5\%; Ni: 12\%; Mo: 2.5\%; Mn: 2\%; Si: 1\%; P: 0.05\%; S: 0.03\%; C: 0.03\%; Fe: balance), $32 \mu \mathrm{m}$ fiber diameter, $0.3 \mathrm{~mm}$ thickness (Southwest Screens \& Filters, Belgium)

- Inconel 601, Bekipor ST20AL3 (composition: Ni: 60.5\%; Cr: 23\%; Al: $1.25 \%$ Cu: 1\%; Mn: 1\%; Si: 0.5\%; C: $0.1 \%$; S: $0.015 \%$; Fe: balance), $8 \mu \mathrm{m}$ fiber diameter, $0.49 \mathrm{~mm}$ thickness (Bekaert Fibre Technology, Belgium)

- Nickel; $12 \mu \mathrm{m}$ fiber diameter, $0.1 \mathrm{~mm}$ thickness (Bekaert Fibre Technology, Belgium)

The filters were used as received. The Ar, $\mathrm{H}_{2}, \mathrm{C}_{2} \mathrm{H}_{6}, \mathrm{~N}_{2}$ were $>99.995 \%$ purity (supplied by Carbagas, Switzerland) and used as received. Nickel nitrate $\left(\mathrm{Ni}\left(\mathrm{NO}_{3}\right)_{2} \cdot 6 \mathrm{H}_{2} \mathrm{O}\right.$, p.a.), methanol and ethanol (both p.a.) were purchased from Fluka, Switzerland. Water was distilled before the use.

\subsection{Growth of carbon nanofibers}

Carbon nanofibers were grown on SMF filters by catalytic pyrolysis (chemical vapor deposition, CVD) of ethane in the presence of hydrogen. The synthesis was carried out in a tubular quartz reactor with $24 \mathrm{~mm}$ internal diameter posed in a tubular furnace. The SMF filters were cut in $24 \mathrm{~mm}$ diameter round slices and one piece was placed perpendicularly to the flow of reagents, at about two-third of the reactor length, ensuring a thermal equilibrium of the gases. The synthesis temperature was monitored by a thermocouple inserted into the reactor within a quartz pipe in contact with the surface of the SMF filter.

All SMF filters were first oxidized in air: $\mathrm{SMF}_{\mathrm{Ni}}$, at $550{ }^{\circ} \mathrm{C}$ for $1 \mathrm{~h}$; $\mathrm{SMF}_{\mathrm{SS}}$ filter, at $550{ }^{\circ} \mathrm{C}$ for $3 \mathrm{~h}$; and $\mathrm{SMF}_{\text {Inconel, }}$, at $650^{\circ} \mathrm{C}$ for $3 \mathrm{~h}$.

$\mathrm{Ni}^{\circ}$ nano-particles were deposed in some cases on SMF filters by impregnation. The filters were dipped in an aqueous solution of nickel nitrate for $5 \mathrm{~min}$, dried in air during $1 \mathrm{~h}$ and subsequently in oven at $125^{\circ} \mathrm{C}$ for $1 \mathrm{~h}$. The concentration of the Ni-solution was calculated based on the SMF wetness capacity of $\sim 23 \%$ to attain $\mathrm{Ni}^{\circ}$ concentration on the SMF filters between 0.2 and 7 wt.\%.

Before the synthesis of the CNF, the SMF filters were reduced in hydrogen $(120 \mathrm{ml}(\mathrm{STP}) / \mathrm{min})$. The temperature was increased $10{ }^{\circ} \mathrm{C} / \mathrm{min}$ and held at $600{ }^{\circ} \mathrm{C}$ for $2 \mathrm{~h}$. Then, the reactor was heated up to the synthesis temperature between 630 and $705^{\circ} \mathrm{C}$, and the CVD mixture was introduced. Standard CNF synthesis mixtures of $\mathrm{C}_{2} \mathrm{H}_{6}: \mathrm{H}_{2}=15: 85$ (flow $120 \mathrm{ml}(\mathrm{STP}) / \mathrm{min}$ ), or of $\mathrm{Ar}_{2} \mathrm{C}_{2} \mathrm{H}_{6}: \mathrm{H}_{2}=80: 3: 17$ (flow $600 \mathrm{ml}$ (STP)/min) were used. The synthesis time was varied between $15 \mathrm{~min}$ and $4 \mathrm{~h}$. A flow of $\mathrm{H}_{2}(120 \mathrm{ml}(\mathrm{STP}) / \mathrm{min})$ was used after processing to prevent the CNF oxidation during the cool down. Reactor pressure was kept at 1.25 bar during the whole process. The carbon yield is defined as the mass of carbon formed on the SMF filter divided by the mass of metal support.

\subsection{Characterization of CNF/SMF composite materials}

The attrition resistance of the carbon nanofibers over filter material was tested using an ultrasonic bath (Bransonic ultrasonic cleaner, HF-output power nom. $30 \mathrm{~W}$, Branson Ultrasonics Corp., USA). The standard procedure after the $\mathrm{CNF}$ synthesis was to treat the resulting $\mathrm{CNF} / \mathrm{SMF}$ composite by ultrasound in methanol during $5 \mathrm{~min}$. All other characterizations were carried out after this step.

The specific surface areas (SSA) of the carbon based composites were measured using $\mathrm{N}_{2}$ adsorption-desorption at $77 \mathrm{~K}$ by a Sorptomatic 1990 instrument (Carlo Erba). Pieces of $100 \mathrm{mg}$ (stainless steel and inconel based composites) or $50 \mathrm{mg}$ (nickel based composite) were cut into $3 \mathrm{~mm} \times 3 \mathrm{~mm}$ slices and placed in the reactor for measurement. The SSA was calculated employing the BET method. To estimate the SSA of CNF synthesized, the SSA of SMF filters was neglected. The BET surface measured for the composite was attributed to the carbon calculated from difference between the mass of the SMF filter and the mass of the resulting CNF/SMF composite. The Dollimore/Heal approach was applied to calculate the pore volume and the pore's size.

The surface morphology of the samples was investigated by scanning electron microscopy, using a JSM-6300F, JEOL. The thickness of the CNF layer on the metallic fibers was estimated by subtraction of the metallic fiber diameter from the CNF/fiber diameter measured on the SEM image. 
Transmission electron microscope, Philips CM300UT FEG, was used to examine the morphology of the CNF. Before analysis, a $3 \mathrm{~mm} \times 3 \mathrm{~mm}$ piece of composite was put in ethanol and ultrasonicated for $15 \mathrm{~min}$ to detach CNF from the surface. Chemical analysis of the catalytic metallic particles present on the CNF was performed by X-ray energy-dispersive analysis (EDS).

The 3D tomography measurements were carried out at the "X-ray Micro-tomography Laboratory" from the National Institute for Lasers, Plasma and Radiation Physics (NILPRP), Bucharest, Romania. The image acquisition, 3D reconstruction and visualization have been carried out by two networked Dual CPU (2 GHz, 2GB) workstations using $\mathrm{X}$-ray source (Phoenix X-ray) at $70 \mathrm{kV}$ and the tube current of $250 \mathrm{~mA}$ [17].

The X-ray diffraction (XRD) patterns of the carbon deposits were recorded by a powder diffractometer (D500, Siemens), using $\mathrm{Cu} \mathrm{K} \alpha$ radiation steps of $2 \Theta=0.04^{\circ}$ and step time of $4 \mathrm{~s}$. The analysis of the composite was impossible because the only peaks visible were those of the metal SMF support. Therefore, CNF needed to be detached from the SMF filters. For that reason, the synthesis time was increased to $240 \mathrm{~min}$ in order to have a thicker CNF layer easier to separate. Then, eight times the ultrasonic treatment for $30 \mathrm{~min}$ in methanol was performed to detach a sufficient amount of CNFs. Then, the methanol was evaporated and the resulting powder analyzed. As an internal standard, $10 \mathrm{mg}$ of $\mathrm{SMF}_{\mathrm{Ni}}$ was added to the CNF powder sample coming from the Inconel filter.

Temperature programmed oxidation (TPO) was carried out via an AutoChem 2910 instrument (Micromeretics SA, Belgium), connected to a mass spectrometer (Pfeiffer Vacuum) for on-line gas detection. The m/e ratios of 18 $\left(\mathrm{H}_{2} \mathrm{O}\right), 28(\mathrm{CO}), 32\left(\mathrm{O}_{2}\right)$ and $44\left(\mathrm{CO}_{2}\right)$ were monitored. The composite samples $(\sim 90 \mathrm{mg})$ were cut into $3 \mathrm{~mm} \times 3 \mathrm{~mm}$ pieces, put into a quartz reactor, and heated in a mixture containing $10 \%(\mathrm{v} / \mathrm{v})$ oxygen in helium with a flow rate of $20 \mathrm{ml} \mathrm{STP} / \mathrm{min}$ and a temperature ramp of $10{ }^{\circ} \mathrm{C} / \mathrm{min}$. The temperature was monitored by a thermocouple placed inside the reactor.

\section{Results and discussion}

\subsection{Synthesis of CNF on SMF filters}

The 3D tomography reconstruction of the oxidized $\mathrm{SMF}_{\text {Inconel }}$ filter is presented in Fig. 1A. The SEM images with different magnifications are shown on Fig. 1B and C. As can be seen, the $\mathrm{SMF}_{\text {Inconel }}$ panels have thickness of $\sim 0.5 \mathrm{~mm}$ and consist of uniform metal fibers of the diameter $d=8 \mu \mathrm{m}$. The filters present an open macro-structure with a porosity of $\sim 81 \%$ and wetness capacity of $\sim 40 \mathrm{wt} . \%$. Some grain boundaries are visible in the highest magnification used (Fig. 1C).

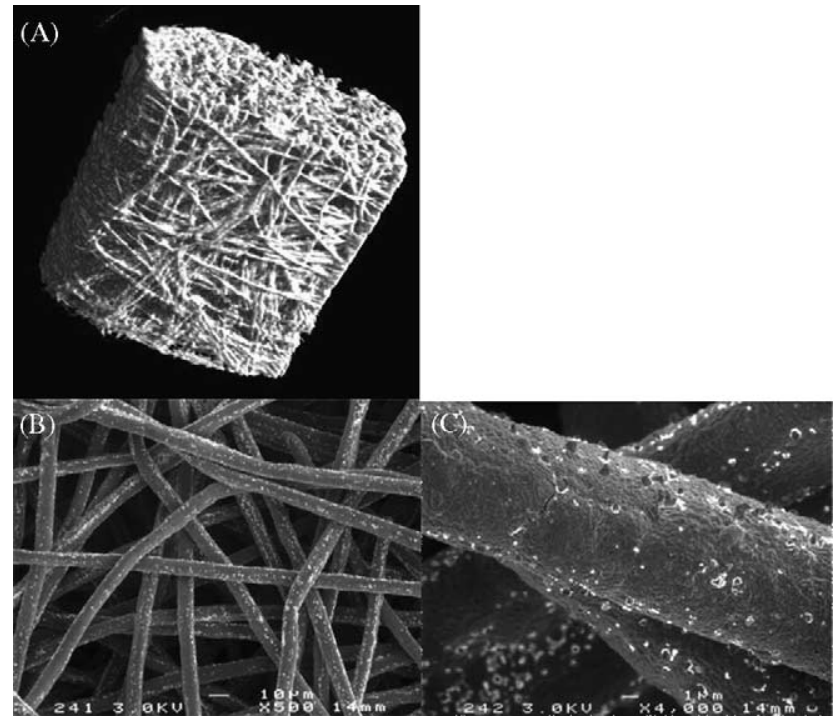

Fig. 1. 3D tomography reconstructions (A) and SEM images: (B) $500 \times$ and (C) $4000 \times$ of the oxidized $\mathrm{SMF}_{\text {Inconel }}$ filters.

As the images suggest, oxidative pre-treatment of the SMF filters not only burns out the protective layer, but creates some surface break-ups and cracks, helping to generate uniform catalyst sites needed for the CNF synthesis. These sites are created after oxidation during surface reduction in hydrogen. The mechanism for the formation of nano-sized catalytic particles and their detachment from the metal surface are still not well understood.

The components of the carbon's precursor gas mixture, the synthesis time and temperature are known to be crucial for CNF synthesis. Therefore, first a mixture of ethylene in hydrogen was fixed with 15:85 ratio, while the temperature and the CVD time were varied. With the Inconel filters, it was observed that an addition of $\mathrm{Ar}(480 \mathrm{ml}$ (STP)/min) to the reaction gas mixture led to an improvement in the homogeneity of the CNF coating. Therefore, a diluted flow of ethane/hydrogen in Ar was used for CNF synthesis over Inconel SMF filters.

Fig. 2 shows the dependence of the CNFs yield on synthesis time for Inconel filters. The results indicate an increase of the carbon formation rate with time. During the first hour, the mass of carbon deposited is roughly proportional to the reaction time with the deposition rate increasing afterwards. This is due to the carbon dissolved in the catalytic metal nano-particles, which would lift up with time creating more cracks. Therefore, the number of surface active sites is increasing in time with concomitant increase of the CNF formation rate.

This work targeted a development of the CNF/SMF composites with acceptable homogeneity. A thin "coating" of CNF is needed, in order to keep the macro-structure and the porosity of the composite material. In this respect, the time of CNF synthesis was explored and the density of carbon deposits was an indicator of efficiency of the 


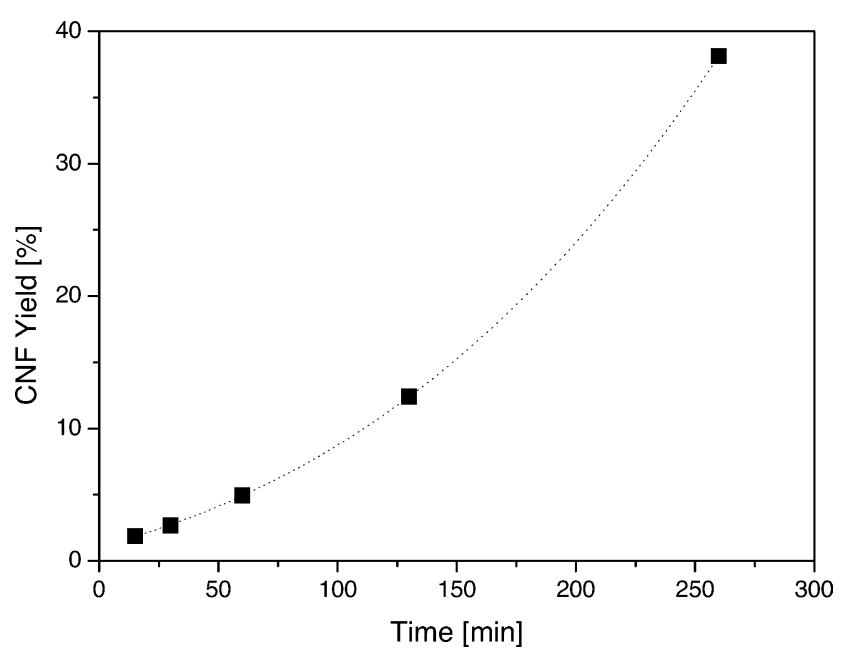

Fig. 2. Carbon yield over $\mathrm{SMF}_{\text {Inconel }}$ filter as a function of the synthesis time at $655{ }^{\circ} \mathrm{C}$ in a mixture of $\mathrm{Ar}_{2} \mathrm{C}_{2} \mathrm{H}_{6}: \mathrm{H}_{2}=80: 3: 17(600 \mathrm{ml}(\mathrm{STP}) / \mathrm{min})$.

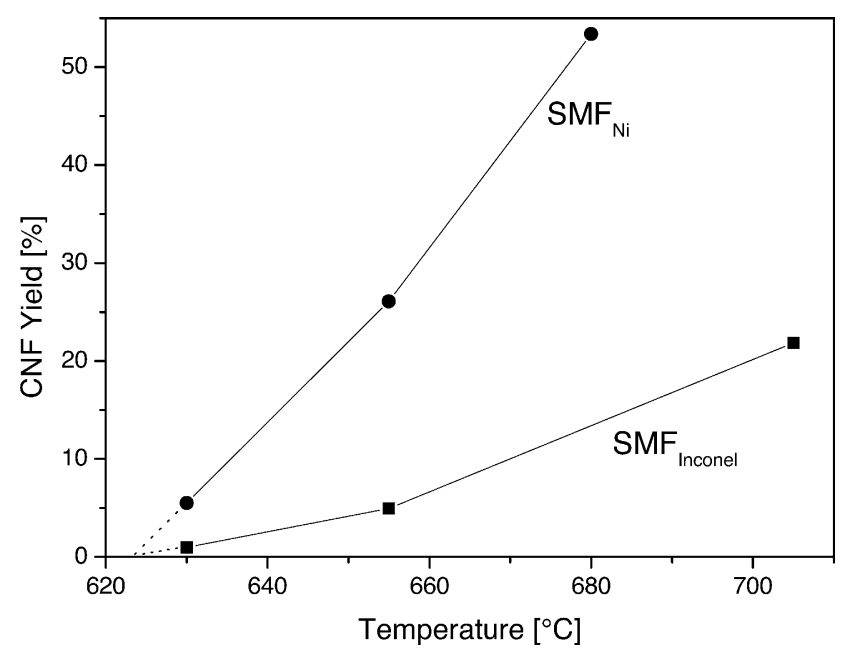

Fig. 3. Carbon yield after $1 \mathrm{~h}$ as a function of synthesis temperature: ( over $\mathrm{SMF}_{\text {Inconel }}$ filter in a $\mathrm{Ar}: \mathrm{C}_{2} \mathrm{H}_{6}: \mathrm{H}_{2}$ mixture $(80: 3: 17,600 \mathrm{ml}(\mathrm{STP}) / \mathrm{min})$; (ם) over $\mathrm{SMF}_{\mathrm{Ni}}$ filter in a $\mathrm{C}_{2} \mathrm{H}_{6}: \mathrm{H}_{2}$ mixture $(15: 85,120 \mathrm{ml}(\mathrm{STP}) / \mathrm{min})$.

synthesis. After $15 \mathrm{~min}$ reaction, the filter was not still covered by carbon as observed by SEM. The CNF synthesis of $30 \mathrm{~min}$ led to a thin but not continuous carbon layer on the SMF surface. Therefore, $1 \mathrm{~h}$ was chosen as an optimal time leading to a homogenous coverage. At longer time $(2 \mathrm{~h})$, the amount of carbon was too high, and after $4 \mathrm{~h}$ a complete blocking of the spaces between fibers was observed. The carbon yield after $1 \mathrm{~h}$ is presented on Fig. 3 as a function of the synthesis temperature for Inconel $\left(\mathrm{SMF}_{\text {Inconel }}\right)$ and nickel $\mathrm{SMF}\left(\mathrm{SMF}_{\mathrm{Ni}}\right)$ filters. The carbon yield on the $\mathrm{SMF}_{\mathrm{Ni}}$ filters was observed to be higher than on $\mathrm{SMF}_{\text {Inconel }}$, using the same gas mixture. Two main reasons can explain this phenomenon. First, nickel is known as the most efficient metal to grow CNF by pyrolisis of hydrocarbons. Second, Inconel alloy contains $\mathrm{Ni}, \mathrm{Fe}$ and also chromium, known to reduce the CNF growth rate as compared to Ni-Fe alloys [18].

An interesting observation is that the ignition temperature for the CNF synthesis is roughly the same $\sim 620{ }^{\circ} \mathrm{C}$ for both SMF filters as seen from Fig. 3. It indicates that at low temperatures nickel is catalyzing the $\mathrm{CNF}$ growth on both surfaces and that the rate on the $\mathrm{SMF}_{\mathrm{Ni}}$ is higher probably due to the higher surface concentration of active sites.

As the sticking properties of the CNFs on the SMF filters are essential for further uses of the composites, the samples were treated in an ultrasonic bath in methanol for $5 \mathrm{~min}$. No carbon came out during this treatment with $\mathrm{CNF} / \mathrm{SMF}_{\text {Inconel }}$ samples. With $\mathrm{CNF} / \mathrm{SMF}_{\mathrm{Ni}}$ samples, less than $5 \%$ of carbon detached during the first 2 min of treatment and nothing came out afterwards. These results prove the excellent anchorage of the CNF on the SMF filters, allowing its use for different applications.

\subsection{Characterization of the CNF/SMF composites}

\subsubsection{Scanning electron microscopy}

Figs. 4-6 show SEM images of the carbon deposits obtained after the CVD processing over stainless steel, $\mathrm{Ni}$, and Inconel SMF filters. With Ni and Inconel, the CVD temperature was $655^{\circ} \mathrm{C}$, while a higher temperature $\left(680{ }^{\circ} \mathrm{C}\right)$ was required with the $\mathrm{SMF}_{\mathrm{ss}}$ filter in order to obtain formation of CNF during a reasonable time. At the lowest magnification $(300 \times, \mathrm{A})$, the macro-structure of the composites is visible. The first observation is that the metal surface is completely covered by a carbon deposit. The second observation is that the homogeneity of CNF coating depends on the support used. For the SS (Fig. 4A) and Inconel filter (Fig. 6A), it appears to be smooth and uniform compared to the Ni filter (Fig. 5A). But it is important to note that the thicknesses of the CNF layers were not the same (see Table 1). When examining the images of Figs. 4-6 (the same magnification), one should take into account that the

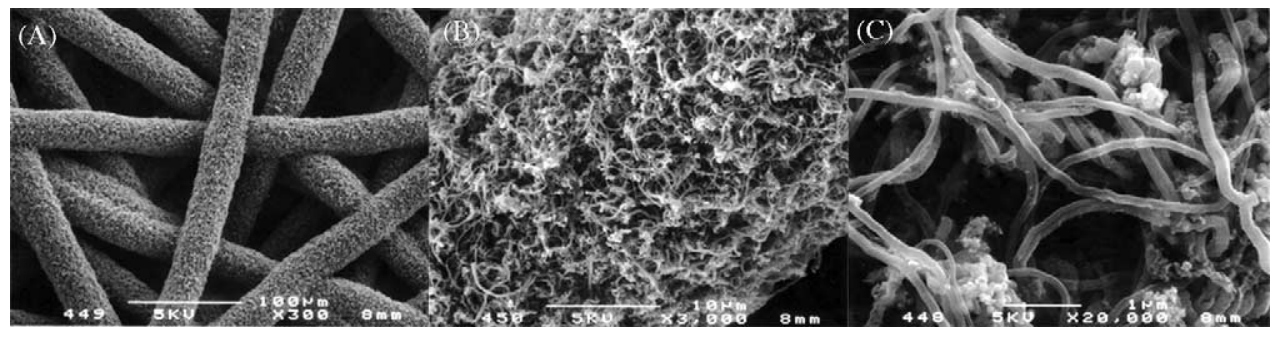

Fig. 4. SEM images (A: $300 \times$, B: $3000 \times$ and C: $20000 \times)$ of carbon nanofibers obtained after $2 \mathrm{~h}$ synthesis over SMF $\mathrm{ss}_{\mathrm{s}}$ at $680{ }^{\circ} \mathrm{C}, \mathrm{C}_{2} \mathrm{H}_{6}: \mathrm{H}_{2}=15: 85(120 \mathrm{ml}$ (STP)/min). 


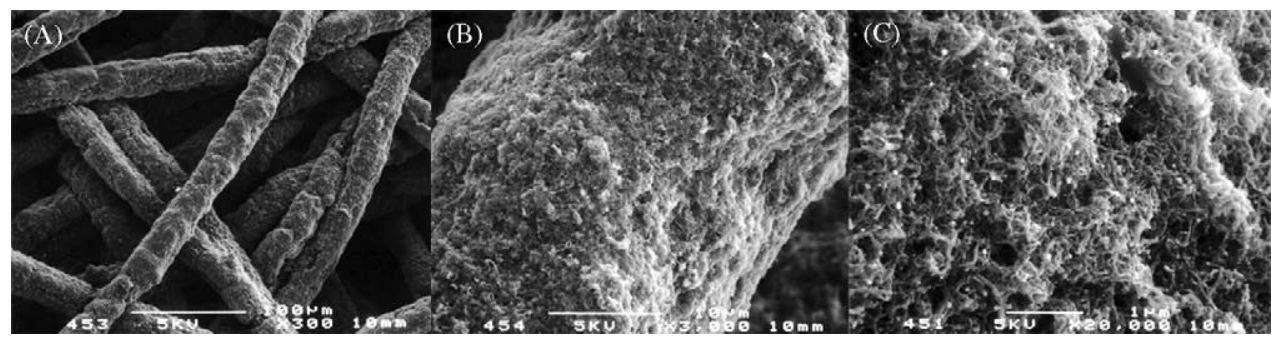

Fig. 5. SEM images (A: $300 \times$, B: $3000 \times$ and C: $20000 \times)$ of carbon nanofibers obtained after $1 \mathrm{~h}$ synthesis over $\mathrm{SMF}_{\mathrm{Ni}}$ at $655^{\circ} \mathrm{C}, \mathrm{C}_{2} \mathrm{H}_{6}: \mathrm{H}_{2}=15: 85(120 \mathrm{ml}$ (STP)/min).

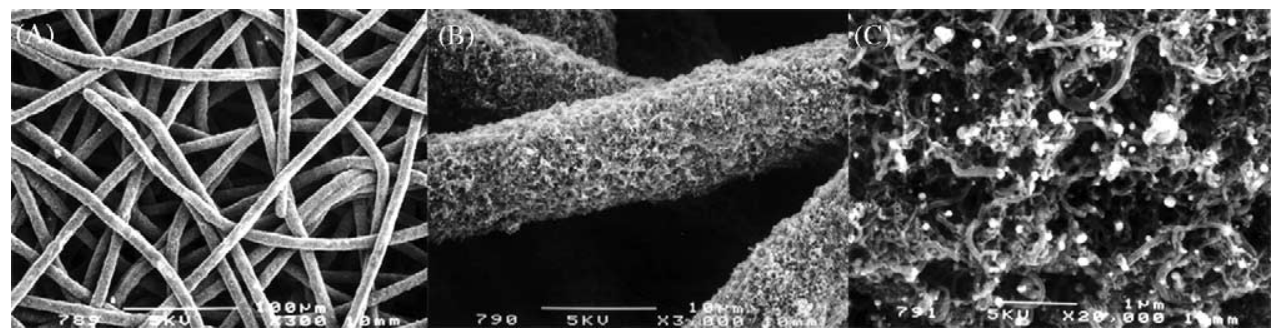

Fig. 6. SEM images (A: $300 \times$, B: $3000 \times$ and C: $20000 \times$ ) of carbon nanofibers obtained after $1 \mathrm{~h}$ synthesis over $\mathrm{SMF}_{\text {Inconel }}$ at $655{ }^{\circ} \mathrm{C}, \mathrm{Ar} \mathrm{C}_{2} \mathrm{H}_{6}: \mathrm{H}_{2}=85: 3: 17$ $(600 \mathrm{ml}(\mathrm{STP}) / \mathrm{min})$.

diameter of SS fibers is about three-fold those of Ni and Inconel. Therefore, the SEM images suggest that the CNF layer is uniform for coatings of $1-2 \mu \mathrm{m}$, becoming less homogeneous for thicker films $(\sim 10 \mu \mathrm{m})$. This observation is consistent with the known mechanism of fiber's growth over Ni metal particles [19]. At the beginning CNF are observed to be straight, but with time become tangled, curved or even twisted.

Since the traditional preparation of CNFs uses supported metal particles, we supported $\mathrm{Ni}^{\circ}$ nano-particles on $\mathrm{SMF}_{\mathrm{Ni}}$ filter for comparison. Fig. 7 shows non-homogenous carbon deposits formed on $7 \% \mathrm{Ni}^{\circ} / \mathrm{SMF}_{\mathrm{Ni}}$ filter after $1 \mathrm{~h}$ in the flow of ethane/hydrogen. In comparison with Fig. 5, presenting the CNF synthesized over $\mathrm{SMF}_{\mathrm{Ni}}$ filter, the carbonaceous layer is much more irregular showing bumps and cracks. The results were observed to be similar and independent of the total nickel concentration and the nature of the support (SS or Inconel SMF). This, probably, reflects the presence of nickel particles of different sizes on the filter surface when formed by deposition. The different size of these $\mathrm{Ni}^{\circ}$ particles seems to be responsible for the CNF nonhomogeneity.

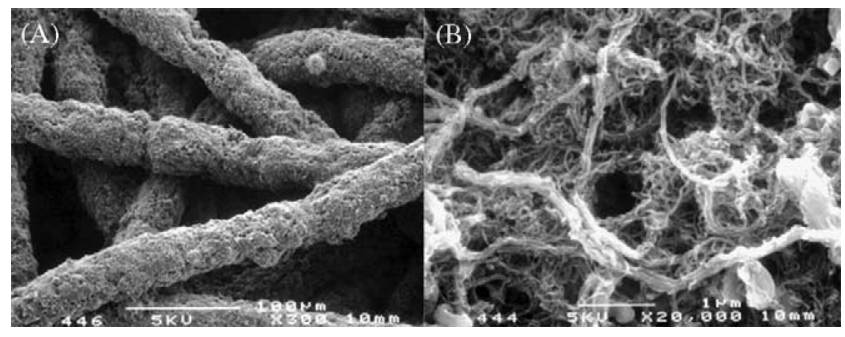

Fig. 7. SEM images (A: $300 \times$ and B: $20000 \times$ ) of carbon nanofibers obtained after $1 \mathrm{~h}$ synthesis over $7 \% \quad \mathrm{Ni} / \mathrm{SMF}_{\text {nickel }}$ at $655^{\circ} \mathrm{C}$, $\mathrm{C}_{2} \mathrm{H}_{6}: \mathrm{H}_{2}=15: 85(120 \mathrm{ml}(\mathrm{STP}) / \mathrm{min})$.

The filamentous morphology of the carbon deposit is seen by zooming on the filters $(3000 \times, \mathrm{B})$. The thickness of the CNF layer can be estimated and the data are shown in Table 1. The difference in the carbon layer thickness was about one order of magnitude indicating a much faster rate of the $\mathrm{C}_{2} \mathrm{H}_{6}$ decomposition over $\mathrm{SMF}_{\mathrm{Ni}}$ filters than in the case of the two other nickel alloys. This agrees with the CNF yields as a function of the reaction temperature and time (see Figs. 2 and 3).

Table 1

Main properties of the CNF/SMF composites after $1 \mathrm{~h}$ synthesis

\begin{tabular}{lllllcrl}
\hline $\begin{array}{l}\text { SMF } \\
\text { catalyst/support }\end{array}$ & $\begin{array}{l}\text { Temperature } \\
\left({ }^{\circ} \mathrm{C}\right)\end{array}$ & $\begin{array}{l}\text { Synthesis } \\
\text { mixture, } \\
\mathrm{C}_{2} \mathrm{H}_{6}: \mathrm{H}_{2}: \mathrm{Ar}\end{array}$ & $\begin{array}{l}\text { Total flow } \\
{[\mathrm{ml} \mathrm{STP} / \mathrm{min}]}\end{array}$ & $\begin{array}{l}\text { Thickness of } \\
\text { carbon layer }(\mu \mathrm{m})\end{array}$ & $\begin{array}{l}\text { Specific surface } \\
\text { area of composite } \\
\left(\mathrm{m}^{2} / \mathrm{g}\right)\end{array}$ & $\begin{array}{l}\text { Specific surface } \\
\text { area of CNFs } \\
\left(\mathrm{m}^{2} / \mathrm{g}\right)\end{array}$ & $\begin{array}{l}\text { Pore volume } \\
\text { of CNFs }(\mathrm{ml} / \mathrm{g})\end{array}$ \\
\hline Stainless steel & 680 & $15: 85: 0$ & 120 & 1.2 & 27.2 & 310 & 0.29 \\
Nickel & 655 & $15: 85: 0$ & 120 & 9.6 & 114.5 & 405 & 0.47 \\
Inconel & 655 & $3: 17: 80$ & 600 & 1.0 & 22.2 & 472 & 0.38 \\
\hline
\end{tabular}


At higher magnification $(20000 \times, \mathrm{C})$, the white dots representing metal particle on the tip of the nanofibers are observed on $\mathrm{SMF}_{\mathrm{Ni}}$ (Fig. 5C) and $\mathrm{SMF}_{\text {Inconel }}$ (Fig. 6C) filters, thus suggesting a "tip growth" mechanism [20]. The stainless steel SMF (Fig. 4C) shows thicker and less homogenous CNFs with several carbon forms present. In addition to filamentous carbon, "bead-like" carbons were visible. Moreover, the white metal dots were not seen, indicating a different CNF growth mechanism.

The chemical composition of the metallic particle present on the tip of the nanofibers grown over $\mathrm{SMF}_{\text {Inconel }}$ filter was investigated by EDS. A mixture containing only nickel and iron in a ratio of $\mathrm{Ni}: \mathrm{Fe}=7: 3$ was found. No chromium was found even its amount in the Inconel alloy is $23 \mathrm{wt} . \%$. This result suggests $\mathrm{Ni}$ and $\mathrm{Fe}$ to be active during the catalytic growth of CNFs. In addition, the Ni:Fe ratio in the tip particle was lower than in Inconel surface being 4.7, meaning that possible iron is the major component of the active particle responsible for catalysis.

\subsubsection{BET surface}

Table 1 presents specific surface areas (SSA) of the CNF/ SMF composites and the SSA of carbon deposits. As seen, the SSA of CNFs found are somehow higher than reported in the literature, for example $\sim 100-250 \mathrm{~m}^{2} / \mathrm{g}[21,22]$. Nevertheless, Lim et al. [23] produced CNF with SSA $>300 \mathrm{~m}^{2} / \mathrm{g}$ by the decomposition of ethylene-hydrogen mixture over $\mathrm{Ni}-\mathrm{Fe}$ catalysts supported on carbon black at temperatures $\sim 580^{\circ} \mathrm{C}$. In our case at higher synthesis temperature (655$680{ }^{\circ} \mathrm{C}$ ) all samples show a high SSA.

The nitrogen adsorption/desorption isotherms measured were characteristic for a mesoporosity. Two main pores diameters were found being around $2 \mathrm{~nm}$ and around $6 \mathrm{~nm}$. These relative small pore's diameters may be due to the formation of CNF bundles and can explain the high SSA observed.

\subsubsection{Transmission electron microscopy (TEM) study}

On the TEM image (Fig. 8) of a carbon nanofiber produced over the nickel filter $\mathrm{SMF}_{\mathrm{Ni}}$, the platelet structure is clearly visible. The diameter of the nanofiber can be estimated being $\sim 20 \mathrm{~nm}$. In addition, the distance between carbon layers can be determined by a direct inspection of the picture. A value of $3.35 \pm 0.1 \AA$ was found, thus confirming the graphitic structure. The CNF formed over Inconel filters led to thicker carbon nanofibers with a diameter about $70 \mathrm{~nm}$. Over the $\mathrm{SMF}_{\mathrm{ss}}$ filter, the diameter of fibers attained 100-150 nm. This thicker fibers obtained with stainless steel can be related to the decrease in SSA shown in Table 1.

\subsubsection{Temperature programmed oxidation (TPO)}

The resistance of carbon materials towards oxidation is important for several applications and relates to the uniformity of the carbon deposits. The ignition temperatures and the oxidation kinetics depend on the form and

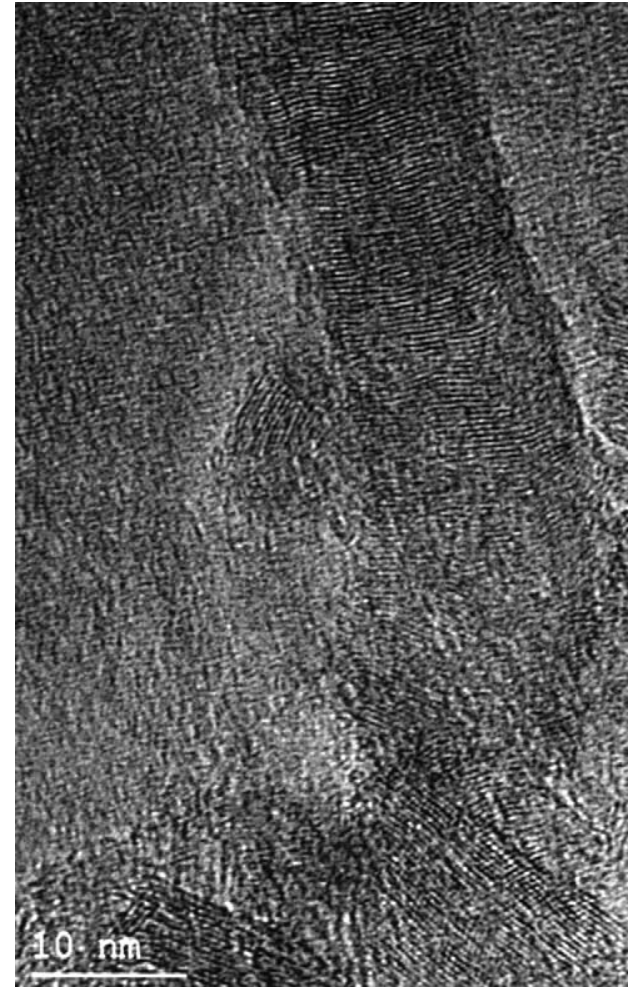

Fig. 8. TEM micrograph of carbon nanofibers obtained at $655^{\circ} \mathrm{C}$ in $\mathrm{C}_{2} \mathrm{H}_{6}: \mathrm{H}_{2}=18: 85(120 \mathrm{ml}(\mathrm{STP}) / \mathrm{min})$ and detached from $\mathrm{SMF}_{\mathrm{Ni}}$.

morphology of the carbon. The obtained CNF/SMF composites were characterized by TPO. The resulting profiles are presented in Fig. 9. Only $\mathrm{CO}_{2}$ was produced during the oxidation. It has to be noticed that the ignition temperature of the sample's oxidation can be affected by the presence of metal, which catalyze the oxidation reaction.

The TPO profiles suggest that no amorphous carbon is present on the CNF/SMF composites, since it is known to burn at around $300{ }^{\circ} \mathrm{C}[24,25]$. There is a notable difference in ignition temperature between the samples, the CNFs on

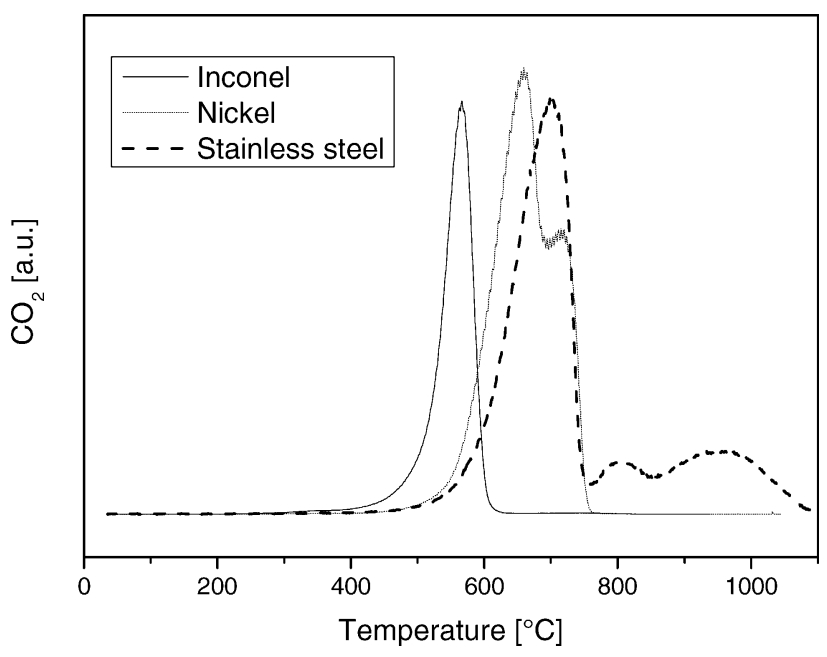

Fig. 9. $\mathrm{TPO}$ of $\mathrm{CNF} / \mathrm{SMF}_{\text {inconel }}, \mathrm{CNF} / \mathrm{SMF}_{\mathrm{Ni}}$ and $\mathrm{CNF} / \mathrm{SMF}_{\mathrm{ss}}$ composites. 
the $\mathrm{SMF}_{\text {Inconel }}$ burning at about $100{ }^{\circ} \mathrm{C}$ lower than the $\mathrm{SMF}_{\mathrm{Ni}}$ and $\sim 150{ }^{\circ} \mathrm{C}$ lower than on $\mathrm{SMF}_{\text {ss. }}$. Wang et al. [25] reported the influence of the fibers diameter on the oxidation temperature: the smaller is the carbon nanofibers diameter, the easier is the oxidation. This is the opposite of what we observed, the fibers diameter being larger in the case of the Inconel filter. Another explanation relates to the crystalline structure of the carbon nanofibers. Park et al. [26] showed that the CNFs produced by decomposition of $\mathrm{C}_{2} \mathrm{H}_{4}-\mathrm{H}_{2}$ mixtures with bimetallic $\mathrm{Ni} / \mathrm{Fe}$ catalyst, have an increased fiber crystallinity in the case of a higher nickel content. This confirms the importance of catalyst composition on fibers morphology. The increased crystallinity leads to a higher stability against oxidation. The Inconel contains $\mathrm{Ni}(60.5 \%)$, $\mathrm{Cr}(23 \%)$ and $\mathrm{Fe}(13 \%)$ as the main components. The uniform TPO profile suggests a uniform type of the carbon nano-fibers, but the reason for the low ignition temperature is not clear. It may reflect a lower degree of crystallinity as compared to $\mathrm{CNF} / \mathrm{SMF}_{\mathrm{Ni}}$, or it may be due to catalyzing effect of $\mathrm{Cr}$ present in $\mathrm{SMF}_{\text {Inconel}}$, which is an active oxidation catalyst.

The TPO profile of the $\mathrm{CNF} / \mathrm{SMF}_{\text {ss }}$ is characterized by the highest ignition temperature of oxidation $\left(\sim 720^{\circ} \mathrm{C}\right)$ as observed on Fig. 5, and this may be due to the thicker diameter of the nanofibers. The existence of two broad satellite peaks at higher temperatures $\left(800\right.$ and $\left.950{ }^{\circ} \mathrm{C}\right)$ confirms the presence of several forms of carbon, as detected previously by SEM on Fig. 4C.

\subsubsection{X-ray diffraction}

The crystalline properties of carbon produced over Inconel and nickel filters were monitored by X-ray diffraction (Fig. 10). The peaks responsible for the diffraction of the graphite 002 planes appear at an angle of $26.63^{\circ}$ for the $\mathrm{CNF} / \mathrm{SMF}_{\text {Inconel }}$ sample and $26.57^{\circ}$ for the $\mathrm{CNF} / \mathrm{SMF}_{\mathrm{Ni}}$ sample. They correspond to the interplanar distances of 3.35 and $3.37 \AA$, respectively, confirming the

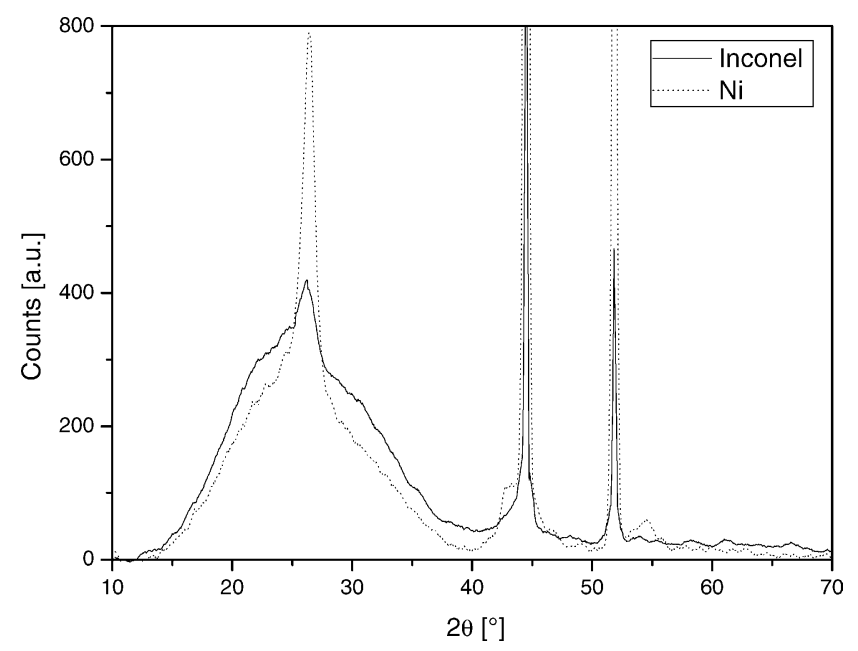

Fig. 10. XRD pattern of carbon powder detached from $\mathrm{CNF} / \mathrm{SMF}_{\text {inconel }}$ and $\mathrm{CNF}_{\mathrm{SMF}} \mathrm{Ni}_{\mathrm{i}}$. estimation obtained from TEM picture. These values are very close to crystalline graphite $(3.348 \AA)$. The small difference found suggests some irregularities present in the fibers as compared to pure graphite. In addition, the relative broadness of the peaks indicates non-homogeneity of the crystalline structure, resulting in peak shift towards higher graphite interplanar distances. The broader 002 peak of $\mathrm{CNF} / \mathrm{SMF}_{\text {Inconel }}$ compared to $\mathrm{CNF} / \mathrm{SMF}_{\mathrm{Ni}}$ indicates a higher degree of crystallinity in the latter case, providing a confirmation of the results found by TPO.

The two sharp peaks monitored for the two samples at angles of $44.3^{\circ}$ and $51.7^{\circ}$ come from metallic nickel support or internal standard (1 11 and 200$)$. The CNF/SMF $\mathrm{Ni}_{\mathrm{Ni}}$ sample shows two other peaks at $43.3^{\circ}(2.09 \AA)$ and $54.4^{\circ}(1.69 \AA)$ which can be attributed to graphite $101(2.027 \AA)$ and 004 $(1.674 \AA)$ planes. The corresponding peaks of the Inconel sample are probably hidden behind the background noise.

\section{Conclusions}

Novel composite materials based on SMF filters coated by carbon nanofibers were synthesized and characterized. The preparation is fast and consists of the decomposition of a $\mathrm{C}_{2} \mathrm{H}_{6}: \mathrm{H}_{2}$ mixture at temperatures between 620 and $680{ }^{\circ} \mathrm{C}$ directly over the SMF filters without deposition of metal particles. The active sites necessary to catalyze the CNF formation are generated by oxidation-reduction of the SMF filter.

The resulting CNF layer is uniform and strongly anchored to the metal surface. The CNFs present a defective graphitic structure as shown by X-ray diffraction. The platelet morphology of CNFs synthesized on $\mathrm{SMF}_{\mathrm{Ni}}$ was observed by TEM. SEM images together with TPO analysis suggested the uniform growth of CNFs on $\mathrm{SMF}_{\text {Inconel }}$ but a mixture of carbon deposits with a different nature on $\mathrm{SMF}_{\mathrm{Ni}}$ and $\mathrm{SMF}_{\mathrm{ss}}$.

The open structure of the parent SMF filters is preserved because the carbon layer is uniform with a thickness of a few microns. In addition, the combination of metallic filter with CNFs coating results in a composite with high thermal conductivity. The properties found are advantageous for the reactors with structured catalytic beds, especially for performing exo/endothermic reactions.

\section{Acknowledgments}

The financial support from the Swiss National Science foundation is gratefully acknowledged. The work of Mr. E. Casali for the $\mathrm{N}_{2}$ adsorption-desorption and Mr. B. Senior for SEM measurements is highly appreciated. We also thank for the 3D tomography experiments Drs. T. Craciunescu and I. Tiseanu from the National Institute for Lasers, Plasma and Radiation Physics (NILPRP), Bucharest, Romania. 


\section{References}

[1] A. Chatterjee, B.L. Deopura, Fiber Polym. 3 (2002) 134.

[2] M. Inagaki, L.R. Radovic, Carbon 40 (2002) 2279.

[3] M. Terrones, Annu. Rev. Mater. Res. 33 (2003) 419.

[4] N.M. Rodriguez, M.S. Kim, R.T.K. Baker, J. Phys. Chem. 98 (1994) 13108.

[5] P. Serp, M. Corrias, P. Kalck, Appl. Catal. A: Gen. 253 (2003) 337.

[6] A. Chambers, T. Nemes, N.M. Rodriguez, R.T.K. Baker, J. Phys. Chem. B 102 (1998) 2251.

[7] F. Salman, C. Park, R.T.K. Baker, Catal. Today 53 (1999) 385.

[8] C.H. Liang, Z.L. Li, J.S. Qiu, C. Li, J. Catal. 211 (2002) 278.

[9] T.G. Ros, D.E. Keller, A.J. van Dillen, J.W. Geus, D.C. Koningsberger, J. Catal. 211 (2002) 85.

[10] C. Park, M.A. Keane, J. Colloid Interface Sci. 266 (2003) 183.

[11] R. Vieira, C. Pham-Huu, N. Keller, M.J. Ledoux, Chem. Commun. (9) (2002) 954.

[12] N.A. Jarrah, J.G. van Ommen, L. Lefferts, J. Mater. Chem. 14 (2004) 1590.

[13] T. Vergunst, F. Kapteijn, J.A. Moulijn, Carbon 40 (2002) 1891.

[14] S. Lim, S.H. Yoon, Y. Korai, I. Mochida, Carbon 42 (2004) 1765.
[15] C.J. Lee, T.J. Lee, J. Park, Chem. Phys. Lett. 340 (2001) 413.

[16] D.R. Cahela, B.J. Tatarchuk, Catal. Today 69 (2001) 33.

[17] I. Tiseanu, T. Craciunescu, B.N. Mandache, Non-destructive analysis of miniaturized fusion materials samples and irradiation capsules by X-ray micro-tomography, in: Proceedings of the 23rd Symposium on Fusion Technology, Venice, Italy, 2004.

[18] Y.-M. Shyu, F. Chau-Nan Hong, Diamond Relat. Mater. 10 (2001) 1241.

[19] K.P. De Jong, J.W. Geus, Catal. Rev. Sci. Eng. 42 (2000) 481.

[20] R.T.K. Baker, Carbon 27 (1989) 315.

[21] C. Pham-Huu, N. Keller, V.V. Roddatis, G. Mestl, R. Schlogl, M.J. Ledoux, Phys. Chem. Chem. Phys. 4 (2002) 514.

[22] M.L. Toebes, J.H. Bitter, A.J. van Dillen, K.P. de Jong, Catal. Today 76 (2002) 33.

[23] S. Lim, S.-H. Yoon, Y. Korai, I. Mochida, Carbon 42 (2004) 1765.

[24] B. Kitiyanan, W.E. Alvarez, J.H. Harwell, D.E. Resasco, Chem. Phys. Lett. 317 (2000) 497.

[25] P. Wang, E. Tanabe, K. Ito, J. Jia, H. Morioka, T. Shishido, K. Takehira, Appl. Catal. A: Gen. 231 (2002) 35.

[26] C. Park, R.T.K. Baker, J. Catal. 179 (1998) 361. 